\title{
The Effectiveness of Health Information Technology on Promoting Medication Adherence in Adults with Diabetes Mellitus Type 2: A Systematic Review Protocol
}

\author{
Claudia Jorge de Sousa Oliveira ${ }^{1,2, *}$, Helena José ${ }^{3}$, Alexandre Castro Caldas ${ }^{1}$, \\ Carolina Gonçalves Venda ${ }^{4}$
}

\author{
${ }^{1}$ School of Nursing-Lisbon, Institute of Health Sciences, Catholic University of Portugal, Portugal \\ ${ }^{2}$ The Portugal Center for Evidence Based Practice: A Joanna Briggs Institute Center of Excellence, \\ Health Sciences Research Unit: Nursing, Nursing School of Coimbra, Portugal \\ ${ }^{3}$ Multiperfil Health School, Angola \\ ${ }^{4}$ Médica Interna de Medicina Geral e Familiar na Unidade de Saúde Familiar Farol da Administração Regional do Algarve, Portugal
}

Copyright $\mathrm{C} 2018$ by authors, all rights reserved. Authors agree that this article remains permanently open access under the terms of the Creative Commons Attribution License 4.0 International License

\begin{abstract}
The objective of this review is to identify the effectiveness of health information technology on promoting medication adherence in adults with diabetes mellitus type 2. More specifically, the review questions are: What is the effectiveness of health information technology on promoting medication adherence in adults with diabetes mellitus type 2? What is the effectiveness of health information technology for enhancing medication adherence in adults with diabetes mellitus type 2 on quality of life? What is the effectiveness of health information technology for enhancing medication adherence in adults with diabetes mellitus type 2 on hospital readmissions?
\end{abstract}

Keywords Medication Adherence, Adult, Middle Aged, Aged, Aged, 80 and over, Diabetes, Intervention, Telemedicine

\section{Introduction}

Chronic diseases are by far, the leading cause of morbidity and mortality in the world, representing $60 \%$ of all deaths [1]. Diabetes mellitus, particularly type 2 , is one of the ten most significant public health care challenges, in terms of prevalence, impact on those living with the disease and costs [2-3]. In other words, diabetes is a worsening epidemic in the worldwide that affected, in 2014, 422 million people in the world, which represent a prevalence of $8.5 \%$ among the adult population [1]. Diabetes is a group metabolic disease characterized by hyperglycemia resulting from defects in insulin secretion, action, or both [4].

According to the Centers for Disease Control and
Prevention, in 2012, over 29 million people or $9.3 \%$ of the population in the United States aged 20 or older had diabetes [5]. More than $80 \%$ of Diabetes related deaths occur in developing countries [6]. Diabetes is a chronic disease requiring lifestyle adjustment, medication regimen and nursing intervention for people can live with quality of life and less complications [7].

In this systematic review our population target are adult people aged of 19 years or older with diabetes. We selected diabetes for two reasons. First, diabetes is a complex illness that requires self-care and self-management with focus on medication adherence to achieve good glycemic control and minimize mortality and morbidity [8]. Secondly, since diabetes is the leading cause of kidney failure, lower-limb amputations and new cases of blindness among adults [5], it is important to promote medication adherence among this population through the comparison of interventions with the common goal [8]. As we know chronic diseases tend to become more common with age, but, nowadays there is an increase in the prevalence rates of this condition among young adults. So, this research aims to synthesize the best scientific knowledge on this field.

In this sense, several chronic disorders including diabetes mellitus are associated with an often-complex medication regimen [9-10]. Medication self-management can be challenging for individuals and the society [11]. Non-adherence is observed, in all groups of patients, where the self-management of treatment is required [12-13], however, the adherence in patients with arthritis, cancer, human immunodeficiency virus infections and gastrointestinal disorders have the highest levels, whereas it is the lowest in patients with diabetes mellitus, pulmonary disease, and sleep disorders [14-15]. The burden of medication non-adherence is a real problem and 
is recognize as one of the leading public health challenges facing the whole world [16]. It has been estimated that half of chronic disease medications are not taken as prescribed on developed countries, the rates in countries in developing is less than $50 \%$ [17-19]. In the United States, half of the 3.2 billion prescriptions dispensed annually are not followed by patients as prescribed [20-21]; this is even lower among patients with chronic disorders [16, 22-23].

Medications adherence has been defined as the extent to which patients take medications as prescribed by their health care providers and decide on the treatment plan [12, $16,24]$, although the lack of adherence to prescribed therapies is termed medication non-adherence [23]. Medication non-adherence is an important health problem which is related with sub-optimal clinical outcomes and increased health-care costs $[10,12,25]$. Even after a prescription has been filled, many patients do not take their medication as prescribed. Up to 1 year after the onset of the drug regimen, more than $50 \%$ of patients prematurely stop their medications [26-28]. This widespread non-adherence has serious consequences al individual and global level, with an increase of complications and costs at the health care systems that serve them [8]. As the result of deteriorating health and adverse events, non-adherence is also correlated with increased hospital admissions and health services utilization [29-31]. Furthermore, the archetypal non-adherent patient needs three additional medical visits per year, yielding an average increase in treatment costs of $\$ 2.000$ annually [32]. It has been estimated that medication non-adherence costs US health care systems between $\$ 100-290$ billion annually [21,33].

Several reasons are documented for the non-adherence to medication, and they may be intentional or unintentional. The causes of non-adherence to medication can be manifold including those which are patient related and health-care system related $[30,34]$. The most common reasons delivered by patients for not taking their medications are forgetfulness, other priorities, deciding to omit a dose, lack of information, and emotional reasons, as forgetfulness assumes the highest rates associated with non-adherence to medication [35].

Health information technology (HIT) presents an opportunity to increase medication adherence rates, through electronic reminders systems. The term HIT refers to the electronic systems healthcare professionals that can be used to store, share and analyze health information. The use of HITs seems to be an aid particularly for patients who are unintentionally non-adherent, like those suffering from forgetfulness [35-36]. Access to mobile technology has grown rapidly in the last two decades and is increasingly being used in the healthcare sector for a variety of purposes [37-38]. Mobile technology has seen many applications in the clinical settings including promoting medication adherence. Among examples are voice reminders, special applications ("apps"), short messaging serve or reminder messages that are automatically sent to a patient's mobile phone in the form of text messaging accessible on every model of mobile phone [39-42].

This reality is intensified because several studies have clearly demonstrated that medication non-adherence can lead patients to unwanted results and adverse events, such as increase morbidity and mortality, increase hospital admissions, decrease quality of life e increase cost [8-10]. The HIT can be a possibility to increase the rates of medication adherence and help patients who lives with Diabetes mellitus type 2 [36].

A preliminary search, on July 2017, of the JBI Database of Systematic Reviews and Implementation Reports, the Cochrane Database of Systematic Reviews, Prospero, CINAHL and Medline revealed that there are currently no systematic reviews (neither published nor in progress) in the effects of HIT on promoting medication adherence among patients with Diabetes.

Therefore, it is necessary to perform a systematic review to determine the effects of HIT on promoting medication adherence among patient with Diabetes mellitus type 2, which involves an intense critical analysis based on scientific evidence. However, it is consensual the need of doing more research in this field.

It is essential to understand the reason of non-adherence to achieve the change of behavior. Non-adherence to medication is a health phenomenon with a huge impact on the practice, especially in primary care, which affects a large number of the elderly $[2,15]$. Nowadays, we have an increase in the older age group with all their needs and, every day, nurses are face to face with them. So, it is imperative that nurses are acquainted with the best available evidence to fight this worldwide problem.

\section{Inclusion Criteria}

\section{Types of Participants}

This review will consider studies that include people aged 19 years and over, of any race, ethnicity, or gender with a diagnosis of Diabetes mellitus type 2, living at home.

\section{Types of Intervention(s)}

This review will consider studies that evaluate the effectiveness of health information technology on promoting medication adherence among older people with Diabetes mellitus type 2 .

\section{Types of Comparator}

This review will consider studies that compare the use of health information technology versus no use of health information technology on promoting medication adherence among older people with Diabetes mellitus type 2 . 


\section{Types of Outcomes}

This review will consider studies that include the following outcomes:

- Primary outcome: Medication adherence, assessed by, but not limited to, any quantitative Medication Adherence Questionnaire (MAQ), for example Medication Adherence Scale (MMAS-8) (Morrisky et al. 1986), Brief Medication Questionnaire (BMQ) (Svarstad et al., 1999), Simplified Medication Adherence Questionnaire (SMAQ) (Knobel et al., 2002), Haynes-Sackett Test (Sackett et al., 1975) and Batalla-martinez Test (Batalla-Martinez et al., 1984). According to each instrument it will be possible to refer the percentage of medication adherence and then a statistical analysis. Each instrument will enable the categorization of the patient as adherent or non-adherent.

- Secondary outcomes:

- Quality of life, assessed by, but not limited to, WHOQoL BREF, and Hospital readmissions;

- Disease complication that can be a bias to HIT and ratio of medication adherence.

\section{Types of Studies}

The review will consider experimental study designs including randomized controlled trials, non-randomized controlled trials, quasi-experimental studies, before and after studies.

\section{Search Strategy}

The search strategy aims to find both published and unpublished studies. A three-step search strategy will be utilized in this review. An initial limited search of MEDLINE and CINAHL will be undertaken followed by an analysis of the text words contained in the title and abstract, and of the index terms used to describe article. A second search using all identified keywords and index terms will then be undertaken across all included databases. Thirdly, the reference list of all identified reports and articles will be searched for additional studies. Studies published in English, Spanish and Portuguese language from 2000 to the present will be considered for inclusion in this review. MEDLINE trend indicates that there are very few studies of health information technology in the medication adherence field prior to 2000, and the first decade of the new century has been characterized by a strong focus on improving health information technology.

The databases to be searched include: PubMed, CINAHL, SCOPUS, Cochrane Central Register of Controlled Trials and Lilacs.

The trial registers to be searched include: ClinicalTrials.gov and ISRCTN registry.
The search for unpublished studies will include: OpenGrey and RCAAP.

Initial keywords to be used will be:

- Diabetes

- Adult

- $\quad$ Middle aged

- $\quad$ Aged

- $\quad$ Aged, 80 and over

- Health information technology

- Text message

- Phone intervention

- Telephone intervention

- Telephone call

- Adherence

- Medication adherence

- Compliance

\section{Assessment of Methodological Quality}

Quantitative papers selected for retrieval will be assessed by two independent reviewers for methodological validity prior to inclusion in the review using standardized critical appraisal instruments from JBI (JBI Critical Appraisal Checklist for Randomized Controlled Trials and JBI Critical Appraisal Checklist for Quasi-Experimental Studies) [43-44]. Any disagreements that arise between the reviewers will be resolved through discussion, or with a third reviewer.

All studies, regardless of their methodological quality, will undergo data extraction and synthesis (where possible).

\section{Data Extraction}

Quantitative data will be extracted from papers included in the review by two independent reviewers using the standardized data extraction tool available in JBI-SUMARI [45]. The data extracted will include specific details about the interventions, populations, study methods and outcomes of significance to the review question and specific objectives. The authors of the primary studies will be contacted to provide missing or additional data. Any disagreements that arise between the reviewers will be resolved through discussion or with a third reviewer.

\section{Data Synthesis}

Quantitative studies will, where possible be pooled in statistical meta-analysis using JBI-MAStARI to provide a statistical summary of the effectiveness of HIT on promoting medication adherence. All results will be subject to double data entry into JBI-SUMARI. Effect sizes expressed as odds ratio (for categorical data) and weighted mean differences (for continuous data) and their 95\% confidence intervals will be calculated for analysis. A t-test might be useful to assess the variability and distribution of 
assessment scores. Heterogeneity will be assessed statistically using the standard Chi-square test and, also explored using subgroup analyses based on the age of the people enrolled in the different selected studies and type of studies. Where statistical pooling is not possible the findings will be presented in narrative form including tables and figures to aid in data presentation where appropriate.

\section{Conflicts of Interest}

There are no conflicts of interest.

\section{Acknowledgements}

This review will partially fulfill degree requirements for successful completion of the Doctor of Nursing Program at Institute of Health Sciences, Universidade Católica Portuguesa, Lisbon, Portugal.

The authors would like to acknowledge the support by the Health Sciences Research Unit: Nursing (UICISA: E), hosted by the Nursing School of Coimbra (ESEnfC), and Foundation for Science and Technology (FCT).

\section{REFERENCES}

[1] World Health Organization. Global report on diabetes. Geneva: World Health Organization. 2016.

[2] Green LW, Brancati FL, Albright A, Primary Prevention of Diabetes Working Group. Primary prevention of type 2 diabetes: integrative public health and primary care opportunities, challenges and strategies. Family Practice. 2012; 29:113-23.

[3] Lee VWY, Pang KKW, Hui KC, Kwok JCK, Leung SL, Yu DSF, Lee DTF. Medication adherence: Is it a hidden drug-related problem in hidden elderly? Geriatr Gerontol Int 2013; 13: 978-85.

[4] American Diabetes Association. Diagnosis and Classification of Diabetes Mellitus. Diabetes Care. 2010; 33(Suppl 1):S62-9.

[5] Centers for Disease Control and Prevention. National Diabetes Statistics Report: Estimates of Diabetes and Its Burden in the United States. Centers for Disease Control and Prevention - Department of Health and Human Services. 2014.

[6] Islam SMS, Lechner A, Ferrari U, Froeschl G, Alam DS, Holle R, Seissler J, Niessen LW. Mobile phone intervention for increasing adherence to treatment for type 2 diabetes in an urban area of Bangladesh: protocol for a randomized controlled trial. BMC Health Services Research. 2014; 14(586):1-9.

[7] Collins AE, Niles BL, Mori DL, Silberbogen AK, Seligowski AV. A Telephone-Based Intervention to
Promote Diabetes Management in Veterans with Posttraumatic Stress Symptoms. Professional Psychology: Research and Practice. 2014; 45(1):20-6.

[8] Zullig LL, Gellad WF, Moaddeb J, Crowley MJ, Shrank, Granger BB, Granger CB, Trygstad T, Liu LZ, Bosworth HB. Improving diabetes medication adherence: successful, scalable interventions. Patient Preference and Adherence. 2015; 9: 139-49.

[9] Russell CL, Ruppar TM, Matteson M. Improving Medication Adherence: Moving from Intention and Motivation to a personal systems approach. Nurs Clin N Am. 2011; 46: 271-81.

[10] Nundy S, Dick JJ, Chou CH, Nocon RS, Chin MH, Peek ME. Mobile Phone Diabetes Project Led to Improved Glycemic Control snd Net Savings For Chicago Plan Participants. Health Affairs. 2014; 33(2):265-72.

[11] Odegard PS, Carpinito G, Christensen DB. Medication adherence program: adherence challenges and interventions in type 2 diabetes. J Am Pharm Assoc. 2013; 53(3): 267-72.

[12] Pai ALH, Drotar D. Treatment adherence impact: the systematic assessment and quantification of the impact of treatment adherence on pediatric medical and psychological outcomes. Journal of Pediatric Psychology. 2010; 35(4):383-93.

[13] Foreman KF, Stockl KM, Le LB, Fisk E, Shah SM, Lew HC, et al. Impact of a text messaging pilot program on patient medication adherence. Clinical Therapeutics. 2012; 34(5): 1084-91.

[14] Henriques MA, Costa MA, Cabrita J. Adherence and medication management by the elderly. Journal of Clinical Nursing. 2012; 21: 3096-105.

[15] Iman M, Saadabadi A, Davood A. Docking studies of phthalimide pharmacophore as a sodium channel blocker. Iran J Basic Med Sci. 2013; 16(9):1016-21.

[16] Osterberg L, Blaschke T. Adherence to medication. N Engl J Med. 2005; 353(5):487-97.

[17] Edmondson D, Horowitz CR, Goldfinger JZ, Fei K, Kronish IM. Concerns about medications mediate the association of post-traumatic stress disorder with adherence to medication in stroke survivors. British Journal of Health Psychology. 2013; 18:799-813.

[18] Haugh, KH. Medication adherence in older adults - The pillbox half full. Nurs Clin N Am. 2014; 49: 183-99.

[19] Makaryus AN, Friedman EA. Patients' understanding of their treatment plans and diagnosis at discharge. Mayo Clin Proc. 2005; 80(8):991-4.

[20] Bosworth HB. Enhancing Medication Adherence: The Public Health Dilemma. Springer Healthcare Communications. 2012.

[21] Lewis A. Non-compliance: a $\$ 100$ billion problem. Remington Rep. 1997; 5(4):14-5.

[22] Braithwaite S, Shirkhorshidian I, Jones K, Johnsrud M. The role of medication adherence in the US healthcare system. Avalore Health LLC. 2013.

[23] Brown MT, Bussell JK. Medication adherence: WHO cares?. 
Mayo Clinic Proc. 2011; 86(4):304-14.

[24] Nieuwlaat R, Wilczynski N, Navarro T, Hobson N, Jeffery R, Keepanasseril A, Agoritsas T, Mistry N, Iorio A, Jack S, Sivaramalingam B, Iserman E, Mustafa RA, Jedraszewski D, Cotoi C, Haynes RB. Interventions for enhancing medication adherence (Review). Cochrane Database of Systematic Reviews. 2014; 11. Art. No.: CD000011.

[25] Doggrell S. Adherence to medicines in the older-aged with chronic conditions: does an intervention concerning adherence by an allied health professional help? Drugs and Aging. 2010; 27(3):239-54.

[26] Granger BB, Bosworth HB. Medication adherence: emerging use of technology. Current Opinion in Cardiology. 2011; 26:279-87.

[27] Shah ND, Dunlay SM, Ting HH, Montori VM, Thomas RJ, Wagie AE, Roger VL. Long-term medication adherence after myocardial infarction: experience of a community. The American Journal of Medicine. 2009; 122(10):961.e7-13.

[28] Vanelli M, Pedan A, Liu N, Hoar J, Messier D, Kiarsis K. The role of patient inexperience in medication discontinuation: a retrospective analysis of medication nonpersistence in seven chronic illnesses. Clinical Therapeutics. 2009; 31(11):2628-52.

[29] McDonnell PJ, Jacobs MR. Hospital admissions resulting from preventable adverse drug reactions. Ann Pharmacother. 2002; 36:1331-6.

[30] Jha AK, Aubert RE, Yao J, Teagarden JR, Epstein RS. Greater adherence to diabetes drugs is linked to less hospital use and could save nearly $\$ 5$ billion annually. Health Aff. 2012; 31(8):1836-46.

[31] Sokol MC, McGuigan KA, Verbrugge RR, Epstein RS. Impact of medication adherence on hospitalization risk and healthcare cost. Med Care. 2005; 43(6):521-30.

[32] Viswanathan M, Golin CE, Jones CD, Ashok M, Blalock SJ, Wines RCM, Coker-Schwimmer EJL, Rosen DL, Sista P, Lohr KN. Interventions to improve adherence to self-administered medications for chronic diseases in the United States: a systematic review. Ann Intern Med. 2012; 157(11):785-95.

[33] Jin J, Sklar GE, Min Sen Oh V, Chuen Li S. Factors affecting therapeutic compliance: A review from the patient's perspective. Therapeutics and Clinical Risk Management. 2008:4(1):269-86.

[34] Julius RJ, Novitsky MA, Dubin WR. Medication adherence: a review of the literature and implications for clinical practice. Journal of Psychiatric Practice. 2009; 15(1):34-44.

[35] Lehane E, McCarthy G. An examination of the intentional and unintentional aspects of medication non-adherence in patients diagnosed with hypertension. Journal of Clinical Nursing- Cardiovascular Nursing. 2007; 16:698-706.

[36] Misono AS, Cutrona SL, Choudhry NK, Fischer MA, Stedman MR, Liberman JN, Brennan TA, Jain SH, Shrank WH. Healthcare Information Technology Interventions to Improve Cardiovascular and Diabetes Medication Adherence. The American Journal of Managed Care, 2010; 16(12 spec no.):SP82-92.

[37] Déglise C, Suggs LS, Odermatt P. SMS for disease control in developing countries: a systematic review of mobile health applications. Journal of Telemedicine and Telecare. 2012; 18(5):273-81.

[38] West D. How mobile devices are transforming healthcare. Center for Technology Innovation - Issues Technology Innovation. 2012; 18:1-11.

[39] Sarabi RE, Sadoughi F, Orak RJ, Bahaadinbeigy K. The Effectiveness of Mobile Phone Text Messaging in Improving Medication Adherence for Patients with Chronic Diseases: A Systematic Review. Iran Red Crescent Med J. 2016; 18(5):1-8

[40] Zolfaghari M, Mousavifar SA, Pedram S, Haghani H. The impact of nurse short message services and telephone follow-ups on diabetic adherence: which one is more effective? Journal of Clinical Nursing. 2012; 21:1922-31.

[41] Sarkar S, Sivashankar P, Seshadri H. Mobile SMS Reminders for Increasing Medication Adherence. International Journal of Pharmaceutical Sciences Review and Research. 2015; 32(1):228-37.

[42] Vollmer WM, Feldstein A, Smith DH, Dubanoski JP, Waterbury A, Schneider JL, Clark S, Rand C. Use of health information technology to improve medication adherence. Am J Manag Care. 2011; 17(12 Spec no.):SP79-87.

[43] Joana Briggs Institute. Joanna Briggs Institute critical appraixal tools for use in JBI Systematic Reviewa: checklist for Randomized Controlled Trials 2016; [internet]. Available

from:http://joannabriggs.org/research/critical-appraisal-tool s.html/. [Acessed September 18, 2017; cited September 18, 2017].

[44] Joana Briggs Institute. Joanna Briggs Institute critical appraixal tools for use in JBI Systematic Reviewa: checklist for Quasi-Experimental Studies 2016; [internet]. Available from:http://joannabriggs.org/research/critical-appraisal-tool s.html/. [Acessed September 18, 2017; cited September 18, 2017].

[45] Joanna Briggs Institute. SUMARI [Computer software]. Adekaude: The Joanna Briggs Institute; 2013. 